[Short Communication]

\section{Lycosid spiders found in coastal waters of}

\section{Japan}

\author{
Yuki G. Baba ${ }^{1 *} \&$ Kenichiro Fujita ${ }^{2}$ \\ ${ }^{1}$ Institute for Agro-Environmental Sciences NARO, 3-1-3 Kan- \\ nondai, Tsukuba-shi, Ibaraki 305-8604, Japan E-mail: ybaba@ \\ affrc.go.jp \\ 2.6 Dorsals Kayak Services, 118-7 Shiomi, Tateyama-shi, Chiba, \\ Japan, 294-0302 \\ *Corresponding author
}

\begin{abstract}
Spiders can be carried out to sea by wind (ballooning on silk) or floods (on flotsam), but this is rarely observed. Here, we report on two wolf spider (Lycosidae) species, Arctosa fujiii Tanaka 1985 and $\mathrm{Hy}$ grolycosa umidicola Tanaka 1978, found at sea within $400 \mathrm{~m}$ of the coast of Tokyo Bay in Chiba Prefecture, Japan. These are two of the few examples of spiders found in coastal waters of Japan.
\end{abstract}

Key words - Asia, human-powered watercraft, rappelling

Spiders are among the most abundant predators in all terrestrial ecosystems (Turnbull 1973; Coddington \& Levi 1991). They are also found on aquatic vegetation (Raizer \& Amaral 2001) and even in freshwater (e.g., Argyroneta aquatica). The only environment that spiders are not known to inhabit is the sea. However, because spiders use ballooning as a way to travel long distances (Gillespie et al. 2012), many spiders could accidentally reach the ocean. In addition, spiders can also drift out to sea on flotsam such as vegetation washed away by floods (Harrison et al. 2017). Although several studies have reported spiders found at sea (Gressitt et al. 1960; Yoshimoto \& Gressitt 1960; Yoshimoto et al. 1962; Holzapfel \& Harrell 1968; Peck 1994; Keynes 2000), in most cases, species (or genus) names have not been identified because the spiders are juveniles, and there are few cases in Asia (e.g., East China Sea in Okuma \& Kishimoto 1981). In addition, many of these studies were based on aerial sampling using capture nets, and few reports the direct observation of spiders at sea. Here, we report on wolf spiders (Lycosidae) found in coastal waters of Japan.

Author KF observed the spiders on 22 November 2006 and 20 February 2020 while kayaking off the coast of Futtsu City (Tokyo Bay) in Chiba Prefecture, Japan. The first individual was found while KF was sailing from Onuki Port to Cape Futtsu. The spider was located at least $200 \mathrm{~m}$ from shore $\left(35^{\circ} 18^{\prime} 6.2^{\prime \prime} \mathrm{N}, 139^{\circ} 48^{\prime} 47.6^{\prime \prime} \mathrm{E}\right.$; open circle in Fig. 1), and was observed walking on the surface of the water like a water strider (Fig. 2A, B). The second individual was found while KF was sailing from the coast of Kazusaminato to Isonezaki. This location ( $35^{\circ} 15^{\prime} 46.44^{\prime}{ }^{\prime} \mathrm{N}, 139^{\circ} 51^{\prime} 5.66^{\prime}$ 'E; filled circle in Fig. 1) is about $380 \mathrm{~m}$ from shore (Fig. 2C, D). The swells were weak on both days, and no drifting objects were seen on the water. Although KF did not capture either spider, he took photos with a digital camera, and the characteristic body marks of these species allowed us to identify them. Both individuals were identified as wolf spiders; that observed in 2006 was identified as Arctosa fujiii Tanaka 1985 and that in 2020 as Hygrolycosa umidicola Tanaka 1978. Arctosa fujiii, which ranges in size from 5 to $8 \mathrm{~mm}$, is widely distributed from flatlands to mountains, and is found in grassy wetlands, woodlands, and their surroundings. $\mathrm{Hy}$ grolycosa umidicola ranges in size from 6 to $8 \mathrm{~mm}$ and is found mainly around wetlands, ponds, and rivers.

The spiders could have reached the ocean through either artificial or natural means. An example of an artificial means would be if individuals fell off a ship after being transported out to sea. This process is consistent with the location of the first individual (A. fujiii), in an area used for seaweed (nori) culture that experiences a large amount of fishing boat traffic. On the other hand, the second individual (H. umidicola) was found in an area where seaweed is not cultured and marine traffic is relatively infrequent. Additionally, it was first spotted some distance in front of the kayak, suggesting that it had not fallen off the kayak. Therefore, the second individual appears unlikely to have been transported out to sea artificially.

Another possibility is that the two spiders reached the sea by natural means such as aerial or drift-mediated dispersal. However, we consider drift-mediated dispersal to be unlikely in this case, because both spiders were found on days when the weather was calm and there was almost no offshore drift from the coast. Therefore, it is reasonable to assume that the spiders were carried out to sea by aerial dispersal.

The dispersal behaviour of these two species is not well understood; however, many other species of wolf spiders are known to use ballooning (Richter 1970; Bonte et al. 2003; Bell et al. 2005). It is worth noting that both individuals were adult or subadult. Adult and subadult wolf spiders, which usually do not balloon owing to aerodynamic constraints, are also known to disperse over short distances by 'rappelling', in which they use bridging silk to descend from high places (Weyman et al. 2002). Recently, however, even relatively large spiders have been observed to balloon (Cho et al. 2018). The coast where the second individual was found is lined with cliffs, and the $2.5-\mathrm{km}$ distance from the Somekawa River to Ishinezaki is a natural coastline with no artificial structures. Because the second spider was discovered relatively close to shore, it may have dispersed from a tall cliff.

To the best of our knowledge, this is the first time that 

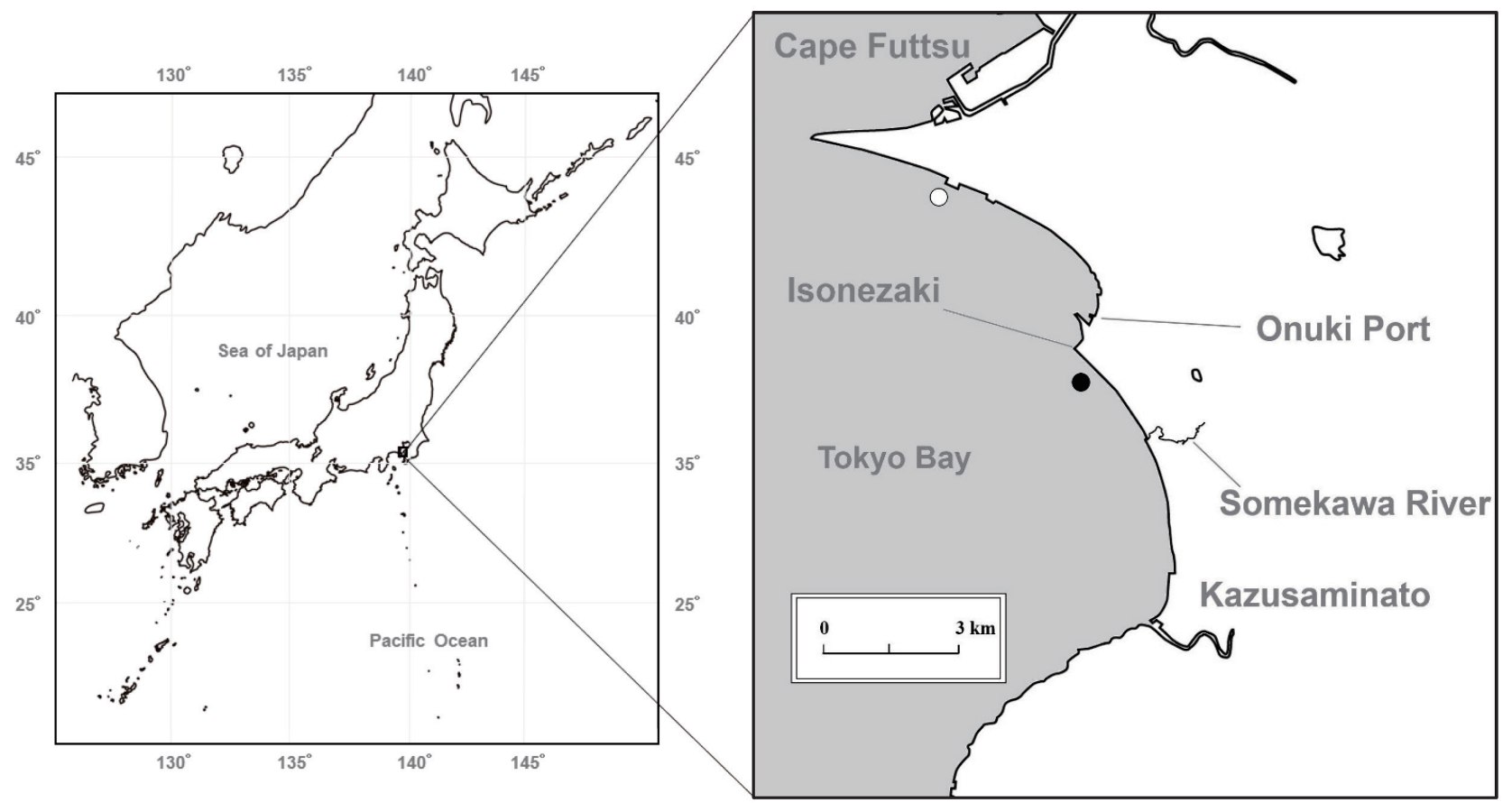

Fig. 1. Locations where the spiders were found at sea. oArctosa fujiii, 2006; • Hygrolycosa umidicola, 2020. The figure is based on a free map downloaded from https://www.freemap.jp/itemFreeDlPage.php?b=japan\&s=japan2

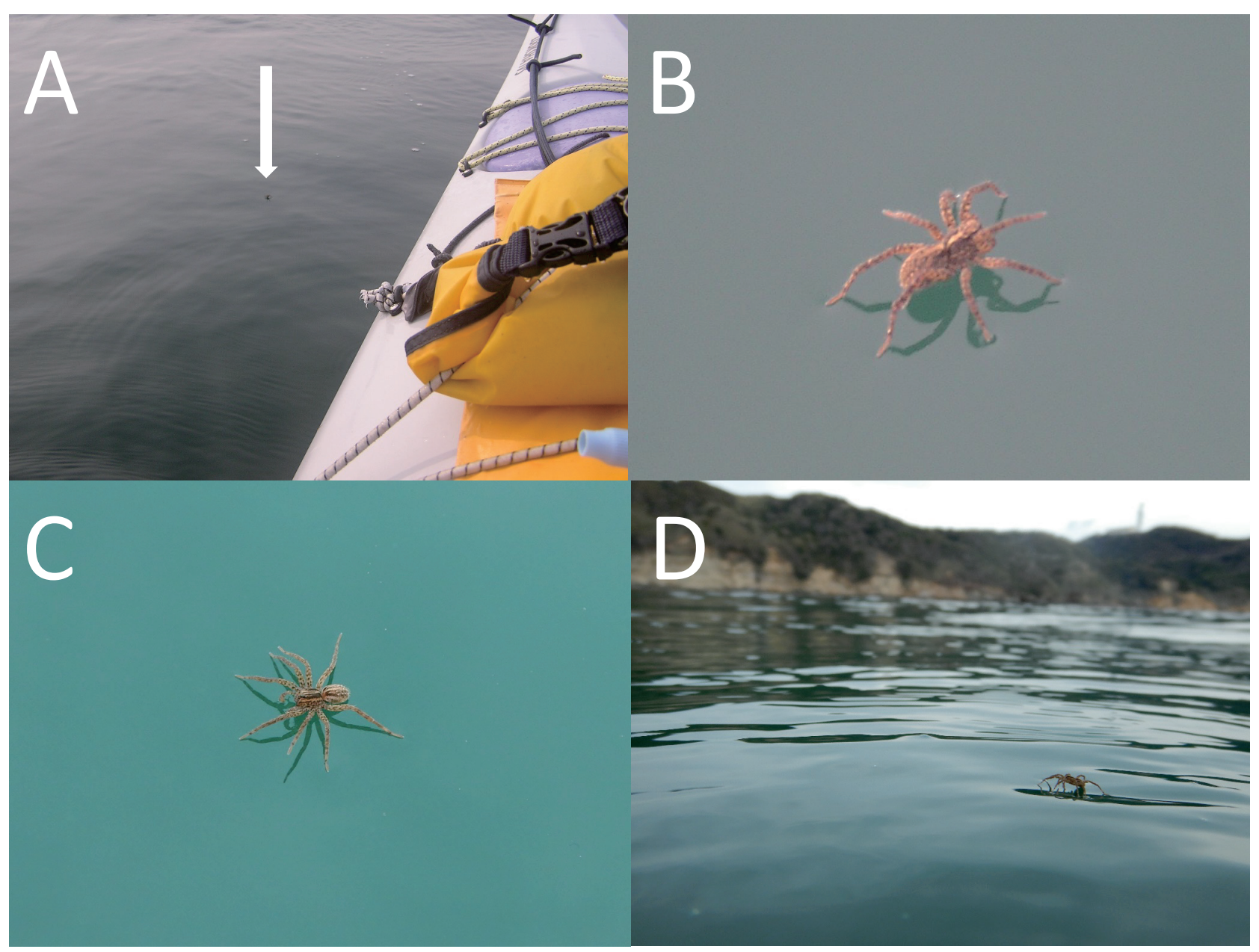

Fig. 2. Photographs of two spiders found at sea. (A, B) Arctosa fujiii, 2006. (C, D) Hygrolycosa umidicola, 2020. 
wolf spiders have been found in coastal waters of Japan and even identified to species level. The fact that wolf spiders of different genera with different habitats were found at sea suggests that transport out to sea is common among lycosid spiders. Because the wolf spider has water-repellent hairs, it can walk on the water surface (Suter et al. 2004). Some spiders are able to surf on seawater using wind propulsion (Hayashi et al. 2015). Therefore, spiders that are accidentally carried out to sea might be able to return to land. This possibility is important for understanding the population dynamics and range expansion of spider species that frequently balloon, and therefore it is important to accumulate observational examples of spiders at sea. Observation from human-powered watercraft such as sea kayaks could be especially fruitful because they provide easy access to the water surface without creating large wakes or disturbances.

\section{References}

Bell, J. R., Bohan, D. A., Shaw, E. M. \& Weyman, G. S. 2005. Ballooning dispersal using silk: world fauna, phylogenies, genetics and models. Bull. Entomol. Res., 95: 69-114.

Bonte, D., Vandenbroecke, N., Lens, L. \& Maelfait, J. P. 2003. Low propensity for aerial dispersal in specialist spiders from fragmented landscapes. Proc. Roy. Soc. London B, 270: 1601-1607.

Coddington, J. A. \& Levi, H. W. 1991. Systematics and evolution of spiders (Araneae). Ann. Rev. Ecol. Syst., 22: 565-592.

Cho, M., Neubauer, P., Fahrenson, C. \& Rechenberg, I. 2018. An observational study of ballooning in large spiders: Nanoscale multifibers enable large spiders' soaring flight. PLoS Biol., 16: e2004405.

Gressitt, J. L., Leech, R. E., \& O’brien, C. W. 1960. Trapping of airborne insects in the Antarctic area. Pac. Insects, 2: 245-250.

Gillespie, R. G., Baldwin, B. G., Waters, J. M., Fraser, C. I., Nikula, R. \& Roderick, G. K. 2012. Long-distance dispersal: a framework for hypothesis testing. Trends Ecol. Evol., 27: 47-56.

Harrison, S. E., Harvey, M. S., Cooper, S. J. B., Austin, A. D. \& Rix
M. G. 2017. Across the Indian Ocean: A remarkable example of trans-oceanic dispersal in an austral mygalomorph spider. PloS One, 12: e0180139.

Hayashi, M., Bakkali, M., Hyde, A. \& Goodacre, S. L. 2015. Sail or sink: novel behavioural adaptations on water in aerially dispersing species. BMC Evol. Biol., 15: 1-8.

Holzapfel, E. P. \& Harrell, J. C. 1968. Transoceanic dispersal studies of insects. Pac. Insects, 10: 115-153.

Keynes, R. D. (Ed.) 2000. Charles Darwin's Zoology Notes \& Specimen Lists from H.M.S. Beagle, Cambridge University Press, pp. 106-108.

Okuma, C. \& Kisimoto, R. 1981. Airborne spiders collected over the East China Sea. Jpn J. Appl. Entomol. Zool., 25: 296-298 [in Japanese].

Peck, S. B. 1994. Sea-surface (Pleuston) transport of insects between islands in the Galápagos archipelago, Ecuador. Ann. Entomol. Soc. Am., 87: 576-582.

Raizer, J. \& Amaral, M. E. C. 2001. Does the structural complexity of aquatic macrophytes explain the diversity of associated spider assemblages? J Arachnol., 29: 227-237.

Richter, C. J. 1970. Aerial dispersal in relation to habitat in eight wolf spider species (Pardosa, Araneae, Lycosidae). Oecologia, 5: 200214.

Suter, R. B., Stratton, G. E. \& Miller, P. R. 2004. Taxonomic variation among spiders in the ability to repel water: surface adhesion and hair density. J. Arachnol., 32: 11-21.

Turnbull, A. L. 1973. Ecology of the true spiders. (Araneomorphae). Ann. Rev. Entomol., 18: 305-348.

Weyman, G. S., Sunderland, K. D. \& Jepson, P. C. 2002. A review of the evolution and mechanisms of ballooning by spiders inhabiting arable farmland. Ethol. Ecol. Evol., 14: 307-326.

Yoshimoto, C. M. \& Gressitt, J. L. 1960. Trapping of air-borne insects on ships on the Pacific (Part 3). Pac. Insects, 2: 239-243.

Yoshimoto, C. M., Gressitt, J. L. \& Mitchell. C. J. 1962. Trapping of air-borne insects in the Pacific-Antarctic area, 1. Pac. Insects, 4: $847-858$.

Received December 16, 2020 / Accepted January 4, 2021 